Exp. Anim. 52(1), 17-24, 2003

\title{
Age-Related Changes on Marking, Marking-like Behavior and the Scent Gland in Adult Mongolian Gerbils (Meriones unguiculatus)
}

\author{
Abliz ARKIN1), Toru R. SAITO1), Kimimasa TAKAHASHI2), Hiromi AMAO1), \\ Shinobu AOKI-KOMORI ${ }^{3)}$, and Kazuaki W. TAKAHASHI ${ }^{1)}$ \\ ${ }^{1)}$ Division of Laboratory Animal Science ${ }^{2)}$ Division of Veterinary Pathology and ${ }^{3)}$ Division of Veterinary \\ Surgery, Nippon Veterinary and Animal Science University, 1-7-1 Kyonan-cho, \\ Musashino-shi, Tokyo 180-8602, Japan
}

\begin{abstract}
Marking behavior, marking-like behavior [3], and changes of the scent glands were observed in aged Mongolian gerbils. In Experiment 1, changes in the marking and marking-like behavior with aging were evaluated in adult male and female Mongolian gerbils of an inbred strain aged 6 to 36 months. The frequency of marking behavior in males was significantly higher than females throughout the observation period except at 36 months of age. On the other hand, frequency of marking-like behavior in males, but not in females decreased with aging, significantly. In Experiment 2, changes of the scent gland in adult males and females aged 6 to 36 months were morphologically evaluated. Macroscopic examination revealed an increase in the size length and width of the glands of males aged 12 months and females aged 6 months. Histologically the glands of all the males and females aged 6 months developed moderately or well. Some of the 12-month-old males and females showed acinar atrophy of the glands, and all the females aged 18 months or more had highly atrophied scent glands. From these results, we concluded that there is no relationship between the changes of marking behavior and those of the scent glands in aged male Mongolian gerbils, and assume that marking behavior in aged animals does not have an important meaning as marking. In Experiment 3, marking and marking-like behavior in castrated adult Mongolian gerbils aged 16 weeks were observed. The result showed that marking behavior, not marking-like behavior was inhibited after castration. From these findings, we consider that generally marking behavior in Mongolian gerbils consists of androgen-dependent marking behavior and androgen-independent marking behavior (marking-like behavior).
\end{abstract}

Key words: aging, marking behavior, marking-like behavior, Mongolian gerbils, scent gland 


\section{Introduction}

Thiessen, et al. [16] reported that marking behavior of mature Mongolian gerbils rubbing secretion containing pheromone of their scent glands toward a small protruding objects, take the role of communicating with one another. It has also been reported that the expression of marking behavior is related to testosterone in males $[5,9,15,18-20]$, and estrogen in females [13, 21]. Marking behavior has been shown to be innate, not learned behavior, for Mongolian gerbils [4], and it is known that the behavior in males is superior to females $[20,25]$. It is also considered that the appearance time of marking behavior is around 82 days of age in males [12], while that in females is still unknown. No detailed paper on marking-like behavior as defined by the authors [3] have been published. In macroscopic observation, there is a significant difference in the appearance time of the scent gland between males and females, and it appears earlier in males than females [3, 10]. Although the structure of the scent glands is histologically similar in both sexes $[2,3,11]$. In most of the above noted, however, only mature animals were subjected to study. Furthermore, in studies on the marking and marking-like behavior through the life time of gerbils, developmental changes of the scent gland with age and the relation between these two behavior and the scent gland are still unknown. Recently, we observed that marking behavior occurred from 40 days of age in males and 50 days in females, and marking-like behavior occurred from 19 days of age in both sexes [3]. We also demonstrated that the scent glands were macroscopically recognizable at 30 days of age in males and at 45 days in females. Histologically, primitively differentiated scent glands were observed at 21 days of age in both sexes, and they matured up to 45 days of age [3].

In the present study, we observed the age-related changes of marking and marking-like behavior (Experiment 1), age-related morphological changes of the scent glands in both sexes of Mongolian gerbils aged 6-36 months (Experiment 2), and the frequency of both behavior in castrated Mongolian gerbils aged 16 weeks (Experiment 3).

\section{Materials and Methods}

Animals: In Experiments 1 and 2, five male and 10 female inbred MGS/Sea Mongolian gerbils (Seiwa Experimental Animals, Ltd., Fukuoka, Japan) were used for breeding, and their offspring (26 males and $25 \mathrm{fe}$ males) were used in this study. The animal were weaned 28 days after birth.

In Experiment 3, 19 males inbred MGS/sea Mongolian gerbils obtained from Seiwa Experimental Animals, Ltd. were used at 16 weeks of age. The animal were kept in an animal room under controlled conditions of $22-26^{\circ} \mathrm{C}$ temperature, $45-65 \%$ relative humidity and $14 \mathrm{~h} \mathrm{(5:00-19:00)}$ artificial lighting. In Experiments 1 and 3 , the animals were individually housed in aluminium mesh cages $(\mathrm{W} 40 \times \mathrm{D} 26 \times \mathrm{H} 23 \mathrm{~cm})$. In Experiment 2, two to 4 animals were housed in aluminium mesh cages. They were given free access to food (MB-1, Funabashi Farm Co. Ltd., Chiba, Japan) and water.

Observation of marking and marking-like behavior (Experiments 1 and 3): For observation of both behavior, according to the method described in previous studies $[3,4]$, the animal was introduced into the individual observation cage made of metal net $(76 \times 46 \times$ $30 \mathrm{~cm})$. A plywood board with two wooden protrusions $(2 \times 1 \times 1 \mathrm{~cm})$ was placed on the floor of each observation cage. Marking and Marking-like behavior were observed for $10 \mathrm{~min}$ between 19:00 and 21:00 under illumination with a red $60 \mathrm{~W}$ light. The "marking behavior" was as follows: the gerbil marked the pegs in the open field by rubbing them with a midventral sebaceous scent gland depositing a yellow-brown sebum over the pegs. And, the "marking-like behavior", as defined by the authors, was characterized by a slight spreading of the fore and hind legs, coupled with a lowering of the abdomen onto the floor of the open field [3]. The frequencies of these behaviors in all animals were averaged respectively. After using it for one animal, the floor plate was cleaned with $70 \%$ alcohol spray and tap water, dried and used for the next animal.

In Experiment 1, four to 8 male and four to 7 female adult Mongolian gerbils were used to observe marking and marking-like behavior at the ages of $6,12,18,24$, 30 and 36 months. Prior to the experiment, vaginal smears from each female were checked and non-recep- 
tive females were selected for both behaviors until 24 months of age.

In Experiment 3, 19 male adult Mongolian gerbils were castrated, then used to observe marking and marking-like behavior. After the animals were quarantined and acclimated under experimental conditions, for 4 weeks, they (16 weeks of age) were divided into three groups: groups A, B and C. They were intact $(n=6)$, castrated-operated with empty tube $(n=7)$, and castratedoperated with $1 \mathrm{~cm}$ length of Silastic tubing $(4.0 \mathrm{~mm}$ in. i.d. $5.5 \mathrm{~mm}$ in. o.d.; Dow-corning. Co., Midland, MI, U.S.A.) ( $\mathrm{n}=6)$ containing $50 \mathrm{mg}$ testosterone propionate (Sigma chemical Co., St. Louis, MO, U.S.A.), respectively. The above operation was performed under anesthesia with pentobarbital sodium $(50 \mathrm{mg} / \mathrm{kg}$, i.p.).

Before castration and at 1, 2, 3 weeks after castration, marking and marking-like behavior were observed in all groups.

Macroscopic and histological examination of the scent glands (Experiment 2): Eighteen males and 18 females were used for macroscopic and histologic examinations of the scent glands. Three males and 3 females were sacrificed with excessive ether anesthesia at the ages of $6,12,18,24,30$ and 36 months. After the abdomen was shaved with a hair clipper, the size (length and width) of the scent gland pad in the midventral line was measured with a micrometer. For histologic examination, the scent glands were removed from the surrounding skin, routinely fixed in $10 \%$ neutral buffered formalin, embedded in paraffin and sectioned at 4-6 $\mu \mathrm{m}$ in thickness. Sections were stained with hematoxylin and eosin (H-E) and examined histologically.

Statistical analysis: Student's $t$-test or Welch's $t$-test was used to test statistical significance in sizes of the scent glands, and the frequency of marking or markinglike behavior was examined by Mann-Whitney $U$ test.

\section{Results}

Observation of marking and marking-like behavior (Experiment 1): Results obtained from mature to aged gerbils are shown in Table 1. The appearance rates of marking behavior were $75-100 \%$ in males and 57.1$100 \%$ in females. No changes with age were observed in either sex. Frequencies of marking behavior at 6, 24 and 36 months of age in males were $10.0 \pm 2.4$ times/ 10 min (mean \pm S.E.), $13.3 \pm 3.3$ and $10.3 \pm 4.1$, respectively, while the values in females were $2.3 \pm 1.2$ at 6 months, $0.9 \pm 0.3$ at 24 months and $1.3 \pm 0.5$ at 36 months of age. There were significant differences in the frequency of marking behavior between both sexes from mature to aged adult gerbils, except at 36 months of age. On the other hand, appearance rates of marking-like behavior were $66.7-100 \%$ in males and $42.9-100 \%$ in females. No changes with aging were observed in either sex. Frequencies of marking-like

Table 1. Age-related changes in marking behavior, and marking-like behavior of adult Mongolian gerbils

\begin{tabular}{|c|c|c|c|c|c|c|}
\hline \multirow{3}{*}{$\begin{array}{c}\begin{array}{c}\text { Age } \\
\text { (Months) }\end{array} \\
6\end{array}$} & \multirow{3}{*}{$\begin{array}{l}\text { Sex } \\
M^{\text {a) }}\end{array}$} & \multirow{3}{*}{$\begin{array}{c}\text { Body } \\
\text { Weight }(\mathrm{g}) \\
\left.72.9 \pm 2.2^{\mathrm{c}}\right)\end{array}$} & \multirow{2}{*}{\multicolumn{2}{|c|}{$\frac{\text { Marking behavior }}{\text { Rate of Frequency occurrence }}$}} & \multirow{2}{*}{\multicolumn{2}{|c|}{$\begin{array}{c}\text { Marking-like behavior } \\
\text { Rate of Frequency occurrence }\end{array}$}} \\
\hline & & & & & & \\
\hline & & & $7 / 8^{d)}$ & $10.0 \pm 2.4 \square^{* \mathrm{e})}$ & $6 / 8$ & $8.1 \pm 2.8$ \\
\hline & $\mathrm{Fb}^{\mathrm{b}}$ & $59.4 \pm 2.5$ & $4 / 7$ & $2.3 \pm 1.2$ & $4 / 7$ & $4.6 \pm 2.2$ \\
\hline \multirow[t]{2}{*}{12} & M & $73.1 \pm 2.0$ & $7 / 8$ & $8.5 \pm 2.0 \square^{* *}$ & $7 / 8$ & $8.4 \pm 1.9$ \\
\hline & $\mathrm{F}$ & $63.7 \pm 2.4$ & $4 / 7$ & $1.3 \pm 0.5$ & $4 / 7$ & $3.6 \pm 1.4$ \\
\hline \multirow[t]{2}{*}{18} & M & $83.5 \pm 4.7$ & $7 / 8$ & $14.6 \pm 3.2 \square^{* * *}$ & $7 / 8$ & $6.1 \pm 2.5 \square *$ \\
\hline & $\mathrm{F}$ & $63.9 \pm 3.0$ & $5 / 7$ & $2.0 \pm 0.7$ & $3 / 7$ & $1.4 \pm 0.8$ \\
\hline \multirow[t]{2}{*}{24} & M & $86.2 \pm 4.5$ & $6 / 6$ & $13.3 \pm 3.3 \square^{* * *}$ & $4 / 6$ & $3.8 \pm 1.6$ \\
\hline & $\mathrm{F}$ & $64.1 \pm 3.7$ & $5 / 7$ & $0.9 \pm 0.3-$ & $4 / 7$ & $1.7 \pm 0.7$ \\
\hline \multirow[t]{2}{*}{30} & M & $83.0 \pm 4.9$ & $5 / 5$ & $15.0 \pm 1.8 \square^{*}$ & $5 / 5$ & $4.6 \pm 1.2$ \\
\hline & $\mathrm{F}$ & $64.8 \pm 5.9$ & $4 / 4$ & $2.0 \pm 0.4$ & $4 / 4$ & $4.3 \pm 1.2$ \\
\hline \multirow[t]{2}{*}{36} & M & $85.0 \pm 5.2$ & $3 / 4$ & $10.3 \pm 4.1$ & $4 / 4$ & $1.8 \pm 0.5$ \\
\hline & $\mathrm{F}$ & $63.8 \pm 5.2$ & $3 / 4$ & $1.3 \pm 0.5$ & $3 / 4$ & $1.3 \pm 0.6$ \\
\hline
\end{tabular}

a) Male ${ }^{\text {b) Female }}{ }^{\text {c) }}$ Mean \pm S.E. ${ }^{\text {d) }}$ Number of animals positive/Number of animals tested ${ }^{\text {e) }}$ Statistically significant difference at *p<0.05, ${ }^{* *} \mathrm{p}<0.01$ (Mann-Whiteny's $U$ test) between the sexes. 
Table 2. Age-related macroscopic changes in the scent glands of Mongolian gerbils

\begin{tabular}{|c|c|c|c|c|}
\hline \multirow{2}{*}{$\begin{array}{c}\text { Age } \\
\text { (Months) }\end{array}$} & \multirow{2}{*}{$\operatorname{Sex}(n)$} & \multirow{2}{*}{ Body weight (g) } & \multicolumn{2}{|c|}{ Scent glands } \\
\hline & & & Length (cm) & Width (cm) \\
\hline \multirow[t]{2}{*}{6} & $M^{\text {a) }}(3)$ & $92.3 \pm 2.3^{\mathrm{c})}$ & $2.9 \pm 0.2 \square^{* d}$ d) & $0.7 \pm 0.0$ \\
\hline & $\mathrm{F}^{\mathrm{b})}$ & $70.7 \pm 2.7$ & $2.1 \pm 0.2$ & $0.4 \pm 0.1-$ \\
\hline \multirow[t]{2}{*}{12} & M (3) & $84.7 \pm 6.8$ & $3.1 \pm 0.3 \square^{* *}$ & $0.7 \pm 0.0 \square$ * \\
\hline & F (3) & $71.7 \pm 2.0$ & $1.6 \pm 0.2$ & $0.4 \pm 0.0-$ \\
\hline \multirow[t]{2}{*}{18} & M (3) & $95.3 \pm 0.9$ & $3.0 \pm 0.2 \square *$ & $0.6 \pm 0.1 \square^{*}$ \\
\hline & F (3) & $74.0 \pm 4.2$ & $1.8 \pm 0.2$ & $0.4 \pm 0.0$ \\
\hline \multirow[t]{2}{*}{24} & M (3) & $89.7 \pm 3.9$ & $2.6 \pm 0.0 \square^{* *}$ & $0.5 \pm 0.1 \square$ * \\
\hline & F (3) & $71.7 \pm 2.3$ & $1.5 \pm 0.1-$ & $0.3 \pm 0.0$ \\
\hline \multirow[t]{2}{*}{30} & M (3) & $92.7 \pm 3.5$ & $2.6 \pm 0.1 \square^{* *}$ & $0.5 \pm 0.0 \square *$ \\
\hline & F (3) & $72.0 \pm 6.1$ & $1.6 \pm 0.0-$ & $0.3 \pm 0.0$ \\
\hline \multirow[t]{2}{*}{36} & M (3) & $92.0 \pm 4.7$ & $2.7 \pm 0.1 \square^{* *}$ & $0.5 \pm 0.1$ \\
\hline & F (3) & $71.0 \pm 4.0$ & $1.5 \pm 0.1$ & $0.3 \pm 0.0$ \\
\hline
\end{tabular}

a) Male b) Female ${ }^{\text {c) }}$ Mean \pm S.E. d) Statistically significant difference at * $p<0.05$, ${ }^{* *} \mathrm{p}<0.01$ (Student's $t$-test or Welch's $t$-test) between the sexes.

behavior in males were $8.1 \pm 2.8 / 10$ min at 6 months, $3.8 \pm 1.6$ at 24 months and $1.8 \pm 0.5$ at 36 months of age. The frequencies in females were $4.6 \pm 2.2$ at 6 months, $1.7 \pm 0.7$ at 24 months, $4.3 \pm 1.2$ at 30 months and $1.3 \pm 0.6$ at 36 months of age. No significant changes with aging were observed in females. There were no significant differences in frequency of markinglike behavior between both sexes, except at 18 months.

Macroscopic examination of the scent glands (Experiment 2): Age-related macroscopic change of the scent glands are shown in Table 2. The average sizes of the scent glands in males of different ages were as follows: $2.9 \pm 0.2 \mathrm{~cm}$ long and $0.7 \pm 0.0 \mathrm{~cm}$ wide $(6$ months); $3.1 \pm 0.3 \mathrm{~cm}$ long and $0.7 \pm 0.0 \mathrm{~cm}$ wide (12 months); $2.6 \pm 0.0 \mathrm{~cm}$ long and $0.5 \pm 0.1 \mathrm{~cm}$ wide (24 months); and $2.7 \pm 0.1 \mathrm{~cm}$ long and $0.5 \pm 0.1 \mathrm{~cm}$ wide (36 months). Those in females were as follows: $2.1 \pm$ $0.2 \mathrm{~cm}$ long and $0.4 \pm 0.1 \mathrm{~cm}$ wide (6 months); $1.6 \pm$ $0.2 \mathrm{~cm}$ long and $0.4 \pm 0.0 \mathrm{~cm}$ wide (12 months); $1.5 \pm$ $0.1 \mathrm{~cm}$ long and $0.3 \pm 0.0 \mathrm{~cm}$ wide (24 months); and $1.5 \pm 0.1 \mathrm{~cm}$ long and $0.3 \pm 0.0 \mathrm{~cm}$ wide (36 months). The values of males were consistently greater than those of females at all the ages examined, except at 36 months of age $(\mathrm{p}<0.05-0.01)$. All the males and females ages 24 months or more showed various degrees of atrophy and hardening of the scent glands.

Histologic examination of the scent glands (Experiment 2): Age-related histologic changes of the scent glands in both sexes are summerized in Table 3 and
Figs. 1 (a-d). All the males aged 6 months had well developed scent glands, of which acinar cells contained a large amount of eosinophilic hyaline droplets in their cytoplasms (Fig. 1 (a)). However, some of the males aged 12 months or more showed mild to severe atrophy of the glands, although others maintained the mature glands. Fibrous tissue was increased around the atrophic acinar cells with advanced age animals. At 36 months of age all the males showed atrophic scent glands (Fig. 1 (b)). In females, moderately or highly developed scent glands were seen at 6 months of age (Fig. 1 (c)). At 18 months or more of age atrophic changes of the glands occurred in all the females and eosinophilic hyaline droplets were almost depleted in the atrophic acinar cells (Fig. 1 (d)). In general, the degree of atrophy of the glands was more severe in females than in males throughout the study period.

Effects of castration on marking and marking-like behavior (Experiment 3): The marking and marking-like behaviors after castration of adult males compared with intact males are shown in Table 4 . Frequencies of marking behavior before castration were $13.3 \pm 2.7 / 10$ min in group A, $14.1 \pm 1.5$ in group B, and $14.9 \pm 2.3$ in group $\mathrm{C}$. The frequencies at three weeks after castration were $13.3 \pm 1.7$ in group A, $4.4 \pm 0.6$ in group $\mathrm{B}$, and $11.0 \pm 2.2$ in group $\mathrm{C}$. The frequency of marking behavior between before and after castration. At 2 and 3 weeks after castration, the value in group B decreased significantly $(p<0.01)$. At one week after 
Table 3. Age-related histologic changes in scent glands of Mongolian gerbils

\begin{tabular}{|c|c|c|c|c|c|c|c|c|c|}
\hline \multirow{2}{*}{$\begin{array}{c}\text { Age } \\
\text { (Months) }\end{array}$} & \multirow{2}{*}{$\begin{array}{c}\text { No. } \\
\text { (Male, Female) }\end{array}$} & \multicolumn{4}{|c|}{ Male } & \multicolumn{4}{|c|}{ Female } \\
\hline & & $\mathrm{M}^{\mathrm{a}}+$ & $\mathrm{M}^{\mathrm{b})}++$ & $\mathrm{A}^{\mathrm{c}}+$, & $\mathrm{A}^{\mathrm{d})}++$ & $\mathrm{M}^{\mathrm{a}}+$ & $\mathrm{M}^{\mathrm{b})_{++}}$ & $\mathrm{A}^{\mathrm{c}}+$ & $\mathrm{A}^{\mathrm{d})}++$ \\
\hline 6 & $(3,3)$ & 3 & & & & 1 & 2 & & \\
\hline 12 & $(3,3)$ & 1 & 1 & 1 & & & & 1 & 2 \\
\hline 18 & $(3,3)$ & & 2 & 1 & & & & & 3 \\
\hline 24 & $(3,3)$ & & 1 & 2 & & & & & 3 \\
\hline 30 & $(3,3)$ & & 2 & & 1 & & & & 3 \\
\hline 36 & $(3,3)$ & & & 3 & & & & & 3 \\
\hline
\end{tabular}

a) M+: Moderately matured. Formation of small acini and acinar cells contain a small number of eosinophic hyaline droplets. ${ }^{\text {b) }} \mathrm{M}++$ : Well matured. Formation of larger acini composed of acinar cells containing a large number of eosinophic hyaline droplets. c) A+: Slightly atrophic. Small acini, with slightly increased fibrous tissue around the acini and acinar cells containing a few exhausted eosinophic hyaline droplets. d) A++: Highly atrophic. Severely decreased number of acini with atrophic acinar cells completely devoid of eosinophic hyaline droplets.
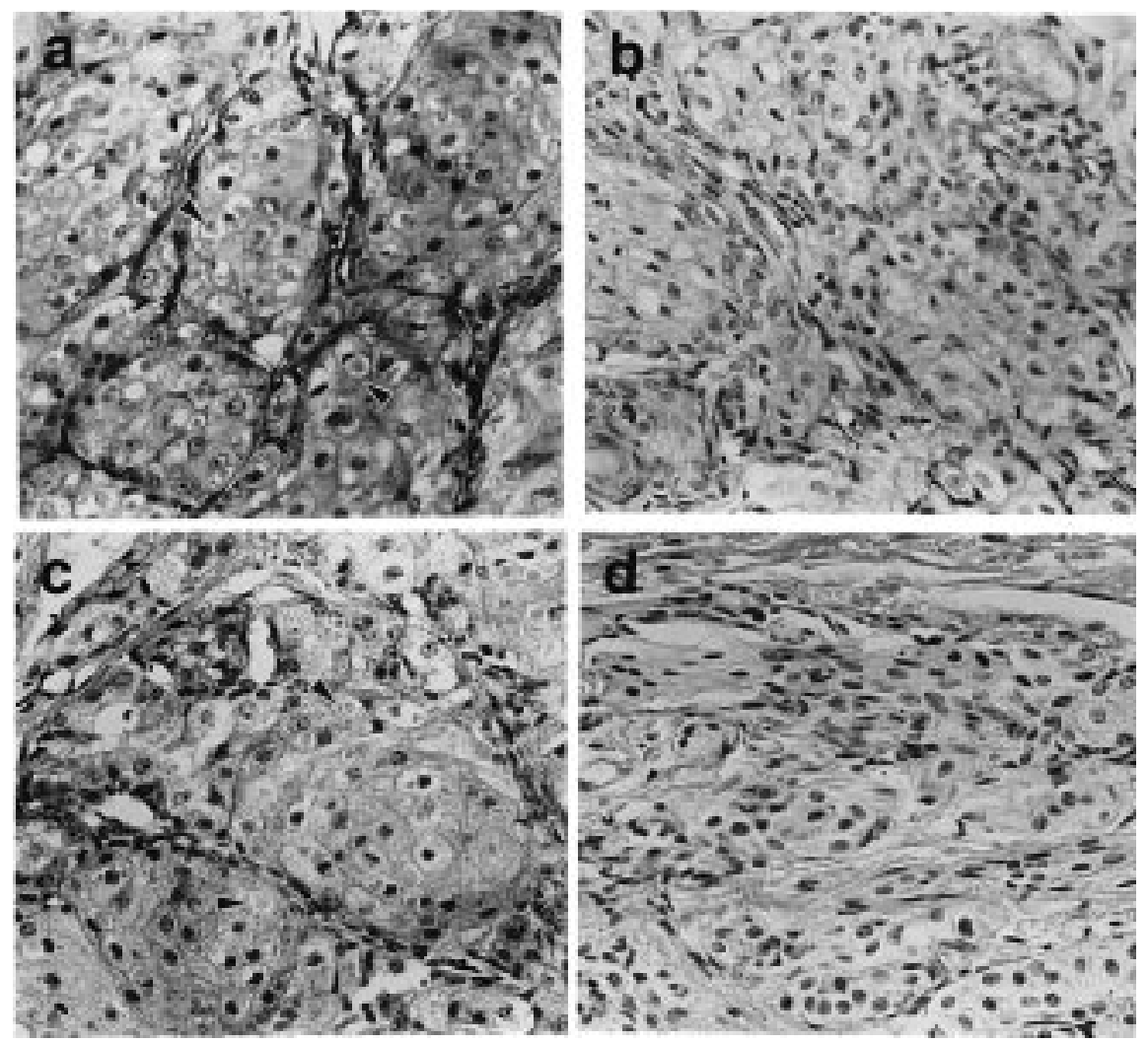

Fig. 1. (a-d) Light micrographs of scent glands in Mongolian gerbils. (a): Male aged 6 months. A lot of the acinar cells contain a large number of eosinophilic hyaline droplets (arrowheads) in their cytoplasms. (b): Male aged 36 months. Some acinar cells show slight atrophy. (c): Females aged 6 months. A lot of the acinar cells contain a large number of eosinophilic hyaline droplets (arrowheads) in their cytoplasms. (d): Females aged 36 months. The acinar cells are highly atrophic and fibrous tissue is increased around them. H-E $\times 860$. 
Table 4. Effect of castration on marking behavior and marking-like behavior of adult Mongolian gerbils

\begin{tabular}{|c|c|c|c|c|c|c|c|}
\hline \multirow{2}{*}{$\begin{array}{c}\text { Observation } \\
\text { Time }\end{array}$} & \multirow{2}{*}{$\begin{array}{c}\text { Body } \\
\text { Weight (g) }\end{array}$} & \multicolumn{3}{|c|}{ Marking behavior } & & \multicolumn{2}{|c|}{ Marking-like behavior } \\
\hline & & \multicolumn{3}{|c|}{ Rate of Frequency occurrence } & & \multicolumn{2}{|c|}{ Rate of Frequency occurrence } \\
\hline \multicolumn{8}{|c|}{ Before castration } \\
\hline $\mathrm{A}^{\mathrm{a})}$ & $82.8 \pm 1.1^{\mathrm{b})}$ & $6 / 6^{\mathrm{c})}$ & $13.3 \pm 2.7$ & & & $5 / 6$ & $13.7 \pm 3.5$ \\
\hline $\mathrm{B}$ & $83.3 \pm 2.1$ & $7 / 7$ & $14.1 \pm 1.5$ & $\square$ & & $7 / 7$ & $8.1 \pm 2.4$ \\
\hline $\mathrm{C}$ & $81.2 \pm 3.0$ & $6 / 6$ & $14.9 \pm 2.3$ & & & $5 / 6$ & $8.3 \pm 2.7$ \\
\hline \multicolumn{8}{|c|}{1 week after castration } \\
\hline A & $88.5 \pm 1.5$ & $6 / 6$ & $16.0 \pm 2.0 \square * \mathrm{~d})$ & & & $6 / 6$ & $7.3 \pm 1.5$ \\
\hline $\mathrm{B}$ & $85.9 \pm 1.5$ & $7 / 7$ & $8.3 \pm 2.1{ }^{* d)}$ & $* *$ & & $6 / 7$ & $6.1 \pm 1.4$ \\
\hline $\mathrm{C}$ & $81.2 \pm 2.9$ & $6 / 6$ & $14.7 \pm 2.7$ & & & $6 / 6$ & $8.7 \pm 2.2$ \\
\hline \multicolumn{8}{|c|}{2 weeks after castration } \\
\hline A & $89.0 \pm 1.0$ & $6 / 6$ & $16.5 \pm 1.2 \square * *$ & & $* *$ & $5 / 6$ & $7.8 \pm 2.3$ \\
\hline $\mathrm{B}$ & $96.1 \pm 1.2$ & $7 / 7$ & $4.6 \pm 1.3=$ & & & $7 / 7$ & $6.1 \pm 1.1$ \\
\hline $\mathrm{C}$ & $84.8 \pm 3.3$ & $6 / 6$ & $11.7 \pm 1.9$ & & & $4 / 6$ & $4.3 \pm 1.9$ \\
\hline \multicolumn{8}{|c|}{3 weeks after castration } \\
\hline A & $92.7 \pm 1.4$ & $6 / 6$ & $13.3 \pm 1.7 \square *$ & & & $5 / 6$ & $6.0 \pm 1.8$ \\
\hline B & $100.0 \pm 1.2$ & $7 / 7$ & $4.4 \pm 0.6 \beth^{*}$ & 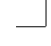 & & $7 / 7$ & $7.0 \pm 1.0$ \\
\hline $\mathrm{C}$ & $93.5 \pm 3.8$ & $6 / 6$ & $11.0 \pm 2.2 \square * *$ & & & $6 / 6$ & $5.8 \pm 1.2$ \\
\hline
\end{tabular}

a) Group A: Sham castrated group, Group B: Castrated and bearing an empty silastic tube buried in the back (skin), Group C: Castrated and bearing a testosterone silastic tube buried in the back (skin), b) Mean \pm S.E. ${ }^{\text {c) }}$ Number of animals positive/Number of animals tested, d) Statistically significant difference at $* \mathrm{p}<0.05$, ** $\mathrm{p}<0.01$ (Mann-Whitney $U$-test).

castration, the frequency in group B decreased significantly ( $\mathrm{p}<0.05)$, compared with group A. At 2 and 3 weeks after castration the value in group B decreased significantly, compared with groups $\mathrm{A}(\mathrm{p}<0.01)$ and $\mathrm{C}$ $(\mathrm{p}<0.05-0.01)$. Frequencies of marking-like behavior before castration were $13.7 \pm 3.5$ in group A, $8.1 \pm 2.4$ in group $\mathrm{B}$, and $8.3 \pm 2.7$ in group C. At 3 weeks after castration the values were $6.0 \pm 1.8$ in group $\mathrm{A}, 7.0 \pm$ 1.0 in group $\mathrm{B}$, and $5.8 \pm 1.2$ in group $\mathrm{C}$. There were no significant differences in frequency of marking-like behavior among the three groups.

\section{Discussion}

In males, the frequency of marking behavior in Mongolian gerbils aged 18, 24 and 30 months tended to increase, when compared with these aged 6 months. The data also showed that marking behavior in aged males was superior to aged females. Turner [20] and Yoshimura [25] demonstrated that marking behavior in matured adult males was superior to females. Turner [20] also reported that sexual domorphism in territorial marking behavior is due to a sex difference in the competency to respond to androgen and that development of this competency occurs during the neonatal period and is regulated, at least in part by androgen. It has been reported that sex hormones regulate marking behavior in adult gerbils [5, 9, 12, 14-24]. Compared with the reproductive ability of gerbils it is possible that the function works until 22-24 months in males [1, 13] and 20-27 months of age in females [1, 6, 13]. These results assumed that the loss in the reproductive ability of aging Mongolian gerbils started with a lowered testosterone or estrogen condition. But, our results showed that marking behavior was not significantly changed with aging in either sex. This finding may indicate that some males and females showed a high-marking behavior in the aged stages. Clark, et al. [7, 8] reported that scent marking was affected by fetal uterine position, and indicated that a portion of the spontaneously occurring variability in the scent-marking behavior of adult male Mongolian gerbils can be accounted for by reference to the uterine position occupied by individual males before birth. Also, Thiessen \& Yahr [18], Thiessen et al. [19], and Ulibarri \& Yahr [21] reported that hypothalamic areas correlate with marking behavior. However, the exact mechanisms of marking behavior in aged Monglian gerbils are un- 
known.

Hamada et al. [11] investigated macroscopically the development of the scent glands in 4-20 week-old gerbils of both sexes. They reported that developed glands were seen in males aged 10 weeks, and in females aged 5 weeks. Our previous study [3], and the present results indicate that the scent glands keep increasing in size up to 12 months of age in males, and 6 months of age in females. However, there was no difference in the maturation age of the scent glands between the data of Hamada, et al. [11] and ours. Some studies reported that there was a sex difference in the development of scent glands [2, 10, 11], and others showed that the development of the scent glands depended on blood testosterone levels in male [10, 12, 14-17], and estrogen levels in females $[14,17,23]$. Our results also indicate that the glands developed better in males than in females at every age throughout the study period $(p<0.05-0.01)$. Histologic examination revealed that the scent glands in all the males and females aged 6 months showed well developed lobules with acinar cells contained a large amount of eosinophilic hyaline droplets in their cytoplasms. However, some of the males and females aged 12 months or more had atrophic scent glands characterized by a decrease in the number of acinar cells and eosinophilic hyaline droplets and by increased fibrous tissue around acini and dilatation of ducts, implying lowered function of secretion. In this study, the atrophic change of the scent glands occurred earlier and more severely in females than in males. It is therefore assumed that marking behavior in aged animals does not have an important meaning as marking.

In the castrated male Mongolian gerbils, frequency of marking behavior, not marking-like behavior, in group B decreased significantly $(\mathrm{p}<0.05-0.01)$, compared with those of groups A and C. While it is well known that marking behavior decreases after castration $[16,18,20]$, no papers have yet described marking-like behavior after castration. From the results, we consider that marking-like behavior is not affected by castration, since there was no significant difference in the frequency of marking-like behavior between the groups. Our previous study [3] showed that the appearance time of marking behavior differed from that of marking-like behavior in young Mongolian gerbils. Lindzey et al. [12] reported that marking behavior appeared clearly around 82 days of age in males
Mongolian gerbils. In the present paper, age-related changes of marking-like behavior were different from those of marking behavior, and marking-like behavior was not directly affected by castration. From these findings, we consider that generally, marking behavior in Mongolian gerbils consists of androgen-dependent marking behavior and androgen-independent marking behavior (marking-like behavior).

Finally, we discuss the relationship between marking behavior and marking-like behavior. Our previous study [3] suggested that marking behavior of the young Mongolian gerbils was first observed at about 40 days of aged in males, and 50 days of age in females, and marking-like behavior was first observed in pups of both sexes aged 19 days of lactation. Lately, we have reported that marking behavior is innate and is not learned behavior in Mongolian gerbils [4]. In adult Mongolian gerbils, marking behavior is defined as gerbils rubbing their abdominal scent glands onto a prominent object $[5,17,18,22,23]$, and both the object and floor $[11,16,20]$. In addition, Thiessen et al. [16] and some researchers [12, 15, 17-20, 22] reported that the open field used for observation had 9 pegs in its $1 \mathrm{~m}^{2}$ floor, while the authors used an $0.34 \mathrm{~m}^{2}$ open field with 2 pegs. Therefore gerbils may have been apt to do marking-like behavior more frequently under those conditions than marking behavior under our experimental condition. Some reports [12, 16] have been discussed the biological significance of marking behavior (it is assumed that marking-like behavior was included), but have not been reported the appearance time and age-related changes of marking behavior. Sexual dimorphism in gerbil scent marking may reflect a difference in the function of the behavior between the sexes. Scent marking by male gerbils appears to be related to territorial maintenance and acquisition, whereas female scent marking may contribute to nest defense and care of the young. Lactating females scent their pups and use these odors during retrieval [22, 24]. Our previous study [3] indicated that marking-like behavior after 45 days old, when the animals had developed their scent glands, played a role of marking.

In summary the present study showed that marking-like behavior was part of the marking behavior, and atrophic change of the scent glands occurred earlier and more severely in females than in males. It also seems that marking behavior in aged animals does not 
have an important meaning as marking. Further, the marking-like behavior was not affected by castration in male Mongolian gerbils.

\section{Acknowledgments}

We would like to thank Dr. N. Moritani for these experiment assistant.

\section{References}

1. Allanson, M. 1970. Gerbils.pp. 237-243. In: Reproduction and Breeding Techniques for Laboratory Animals (Hafez, E. S. E. ed), Lea \& Febiger. Philadelphia.

2. Aoki-Komori, S., Saito, T.R., Umeda, M., Sugiyama, M., Takahashi, K.W., and Taniguchi, K. 1994. Lectin histochemical studies on the scent gland in the Syrian hamster and Mongolian gerbil. Exp. Anim. 43: 181-190 (in Japanese).

3. Arkin, A., Saito, T.R., Takahashi, K., Sugiyama, M., AokiKomori, S., Amao, H., and Takahashi, K.W. 1999. Observation of marking-like behavior, marking behavior, and growth of the scent gland in young Mongolian gerbils (Meriones unguiculatus) of an inbred strain. Exp. Anim. 48: 269-276.

4. Arkin, A., Saito, T.R., Takahashi, K., Amao, H., and Takahashi, K.W. 2000. Marking behavior is innate and not learned in the Mongolian gerbil. Exp. Anim. 49: 205-209.

5. Blum, S.L. and Thiessen, D.D. 1971. The effect of different amounts of androgen on scent marking in the male Mongolian gerbil. Horm. Behav. 2: 93-105.

6. Cheal, M. 1983. Life span ontogeny of breeding and reproductive success in Mongolian gerbils. Lab. Anim. 17: 240-245.

7. Clark, M.M., Malenfant, S.A., Winter, D.A., and Galef, B.G. Jr. 1990. Fetal uterine position affects copulation and scent marking by adult male gerbils. Physiol. Behav. 47: 301-305.

8. Clark, M.M., Bishop, A.M., Vom Saal, F.S., and Galef, B.G. Jr. 1993. Responsiveness to testosterone of male gerbils from known intrauterine positions. Physiol. Behav. 53: $1183-1187$.

9. Commins, D. and Yahr, P. 1984. Adult testosterone levels influence the morphology of a sexually dimorphic area in the Mongolian gerbil brain. J. Comp. Neurol. 224: 132140 .

10. Glenn, E.M. and Gray, J. 1965. Effect of various hormones on the growth and histology of the gerbil (Meriones unguiculatus) abdominal sebaceous gland pad. Endocrinology. 76: 1115-1123.

11. Hamada, Y., Okada, T., and Kanabayashi, T. 1992. Developmental study of the ventral scent gland of the Mongolian gerbil. Exp. Anim. 41: 545-548.

12. Lindzey, G., Thiessen, D.D., and Tucker, A. 1968. Development and hormonal control of territorial marking in the male Mongolian gerbil (Meriones unguiculatus). Dev. Psychobiol. 1: 97-99.

13. Marston, J.H. and Chang, M.C. 1965. The breeding, management and reproductive physiology of the Mongolian gerbil (Meriones unguiculatus). Lab. Anim. Care. 15: 3448.

14. Owen, K. and Tiessen, D.D. 1973. Regulation of scent marking in the female Mongolian gerbil Meriones unguiculatus. Physiol. Behav. 11: 441-445.

15. Thiessen, D.D. 1968. The roots of territorial marking in the Mongolian gerbil: A problem of species-common topography. Behav. Res. Meth. \& Instru. 1: 70-76.

16. Thiessen, D.D., Friend, H.C., and Lindzey, G. 1968. Androgen control of territorial marking in the Mongolian gerbil. Science 160: 432-433.

17. Thiessen, D.D. and Lindzey, G. 1970. Territorial marking in the female Mongolian gerbil: Short-term reactions to hormones. Horm. Behav. 1: 157-160.

18. Thiessen, D.D. and Yahr, P. 1970. Central control of territorial marking in the Mongolian gerbil. Physiol. Behav. 5: 275-278.

19. Thiessen, D.D., Yahr, P.I., and Owen, K. 1973. Regulatory mechanisms of territorial marking in the Mongolian gerbil. J. Comp. Physiol. Psychol. 82: 382-393.

20. Turner. J.W., Jr. 1975. Influence of neonatal androgen on the display of territorial marking behavior in the gerbil. Physiol. Behav. 15: 265-270.

21. Ulibarri. C. and Yahr, P. 1996. Effects of androgens and estrogens on sexual differentiation of sex behavior, scent marking, and the sexually dimorphic area of the gerbil hypothalamus. Horm. Behav. 30: 107-130.

22. Wallace, P., Owen, K., and Thiessen, D.D. 1973.The control and function of maternal scent marking in the Mongolian gerbil. Physiol. Behav. 10: 463-466.

23. Yahr, P. and Thiessen, D.D. 1975. Estrogen control of scent marking in female Mongolian gerbils (Meriones unguiculatus). Behav. Biol. 13: 95-101.

24. Yahr, P. 1975. Effects of hormones and lactation on gerbils that seldom scent marking spontaneously. Physiol. Behav. 16: 395-399.

25. Yoshimura, H. 1981. Behavioral characteristics of scent marking behavior in the Mongolian gerbil (Meriones unguiculatus). Exp. Anim. 30: 107-112. 